\title{
A infoera \\ transformando \\ as relações sociais
}

\section{Para o professor e pesquisador João Antonio Zuffo, a infoera modificará profundamente nosso modo de ser e imporá novos valores e formas de interação social}

João Antonio Zuffo, quando garoto, pensava em ser químico. No fundo de sua casa havia um laboratório de química onde arquitetava a construção de bombas caseiras e deliciava-se fazendo foguetes. "Na década de 1950, a criançada tinha fácil acesso a produtos químicos. Lembro-me de comprar na Botica ao Veado D’ouro. Em casa fazia hidrogênio, clorato de potássio. Cheguei até a comprar ácido fluorídrico. Meu avô, com medo de uma explosão, construiu um laboratório no fundo do quintal, longe de tudo", conta Zuffo.

Prevendo coisa pior do que a explosão, que realmente chegou a acontecer no laboratório, sua mãe mudou o rumo da história inscrevendo-o numa escola de eletrônica por correspondência, na época chamada Instituto Monitor. Desde então Zuffo, como é mais conhecido, saiu da área química e ingressou de corpo e alma na eletrônica, e daí para a frente não parou mais.

Na década de 1970, já atuando como professor da Escola Politécnica de Engenharia Elétrica da USP, foi um dos fundadores do Laboratório de Microeletrônica, tendo construído o primeiro circuito integrado da América Latina, em abril de 1971. Atualmente é professor titular da Poli e coordenador-geral do Laboratório de Sistemas Integráveis - LSI, que, desde 1995, vem desenvolvendo pesquisas na área de supermicrocomputadores, estações de trabalho, osciloscópios digitais e analisadores lógicos. Também orienta teses nas áreas de microeletrônica e sistemas eletrônicos digitais, com ênfase em supercomputação paralela e distribuída e também computação gráfica.

Autor de 15 livros, entre os quais A infoera: o imenso desafio do futuro (1997), o professor João Antonio Zuffo, em entrevista a Comunicação \& Educação, de sua sala no LSI, falou sobre a internet ligando o mundo e construindo uma grande e única rede mundial; da informática revolucionando as atividades humanas, principalmente o ensino fundamental, médio e superior da importância do ensino a distância com tecnologia brasileira e das mudanças acarretadas com o advento da TV digital.

Por Izabel Leão 
1. Gigaflops é a medida de velocidade do computador. Um gigaflop equivale a um bilhão de operações de ponto flutuante por segundo (Floating-point Operations Per Second). (N. E.)

2. Sinapse é a estrutura dos neurônios através da qual ocorrem os processos de comunicação entre eles, ou seja, em que ocorre a passagem do sinal neural (transmissão sináptica) através de processos eletroquímicos específicos, isso graças a certas características particulares da sua constituição. (N. E.)
RGE: Como foi construir o primeiro circuito integrado da América Latina numa época sem muitos recursos tecnológicos?

João Zuffo: No final de 1969, recebemos ao mesmo tempo a visita do CNPq, BNDES e Fapesp e aproveitamos para fazer o pedido de construção de um laboratório a fim de desenvolver em série esse circuito integrado. Em abril de 1970, inauguramos o Laboratório de Microeletrônica da USP - LME. Um ano depois fiz o primeiro circuito integrado. Naquela época não estávamos tão atrasados em relação ao exterior, que teve seu primeiro circuito integrado por volta de 1960, dez anos antes do nosso. Em 1976 fundei o Laboratório de Sistemas Integrados (LSI), baseado no que eu tinha previsto na livre-docência: os sistemas integrados de um milhão de componentes, que agora estão em um bilhão. Não existiam softwares nem computadores. Para se ter uma idéia, um computador tipo IBM 370 possuía um milésimo da capacidade de processamento do que nós temos num micro hoje, cuja capacidade é de um gigaflop ${ }^{1}$.

RCE: Até onde vai chegar a capacidade dos computadores?

João Zuffo: A tendência é crescer mil vezes dentro de dez anos, para as próximas décadas. Podemos dizer que até 2010, 2012, os supercomputadores terão a mesma capacidade de processamento que o cérebro humano. E até 2020, o micro irá adquirir essa mesma capacidade de processamento.

RCE: Mas a capacidade do cérebro humano já foi dimensionada?

João Zuffo: Podemos dimensionar essa capacidade pelo número de neurônios que há no cérebro. Calcula-se que existam alguns bilhões de neurônios pela dimensão do cérebro, pela dimensão dos neurônios, pelo número de sinapses ${ }^{2}$, que ocorre entre os neurônios e a velocidade de propagação de sinais nas sinapses, que é da ordem de 20 microssegundos. A propagação desses sinais é mais ou menos lenta entre as várias sinapses e os vários neurônios. Verificou-se que isso é que dá a capacidade de processamento, tornando os supercomputadores mais velozes.

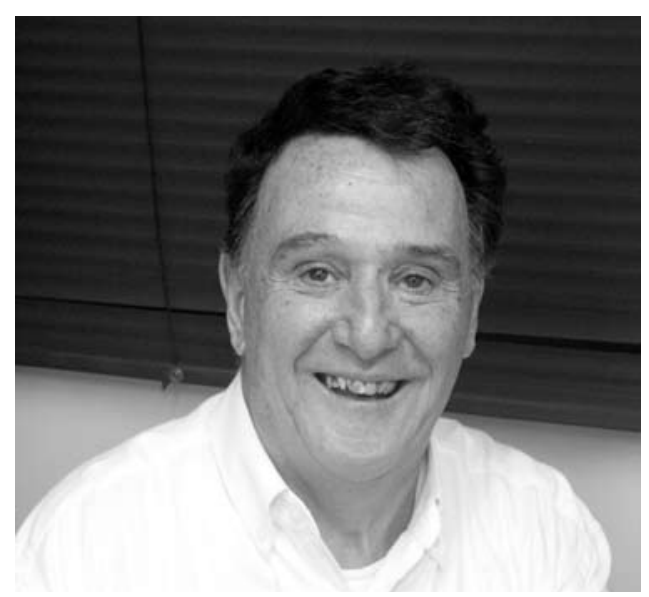

O prof. Zuffo acredita que os computadores irão aumentar sua capacidade em mil vezes dentro de dez anos. 
RCE: Sabemos que não usamos nem um terço de nossa capacidade cerebral. Como vamos usar toda essa capacidade em um computador?

João Zuffo: É o que chamamos de inteligência artificial. Por exemplo, existe uma aplicação denominada algoritmo genético ${ }^{3}$. Você coloca as condições de contorno, uma série de seres virtuais e também as condições de sobrevivência desses seres, como se fosse na vida real. Esses seres vão evoluindo em milhões de gerações e pode ser que cheguemos num ser inteligente virtualmente, que tenha a mesma capacidade de processamento que o cérebro humano. Usa-se isso hoje em seres artificiais para gerenciar recursos financeiros, sendo mais eficientes que os humanos.

RCE: É isto então que o senhor denomina de infoera?

João Zuffo: A infoera é a era da informação que está mudando os valores da sociedade e o relacionamento humano. Eu diria que é a mudança mais profunda ocorrida na história da humanidade. Quando comecei a gerenciar o Laboratório de Sistemas Integráveis da Poli, percebi o início de uma mudança no relacionamento social. Por exemplo, o nosso laboratório, inicialmente, era uma área restrita à engenharia. Quando recebemos o primeiro computador gráfico, vários artistas começaram a aparecer por aqui, como é o caso dos Titãs que fizeram ingressos de um show no computador. Isso me mostrou que havia um comportamento diversificado; aquilo que era considerado uma máquina estranha estava se dissolvendo completamente. Os conceitos sociais estão em constante mudança. A hierarquia é uma delas. Na era industrial, ela era necessária. Nessa época havia o setor que criava, o capataz, o operário, cada um com sua função definida. Essa forma de hierarquia se irradiou para todos os níveis da sociedade. Depois da Segunda Guerra Mundial, a qual chamamos de era pós-industrial, vieram as tecnologias de informação. Surgiram o telefone mais eficiente, as estradas mais eficientes. Isso tudo tem contribuído para que essas hierarquias comecem a se dissolver. Na era da informação, a qual denomino de infoera, devido à propagação muito rápida de informações, a hierarquia vai desaparecer totalmente $\mathrm{e}$ ficará um esquema mais ou menos horizontal de associação. As pessoas serão valorizadas pela sua capacidade, e não pela posição que ocupam.

RCE: O senhor acredita que as relações familiares vão mudar?

João Zuffo: Aliás, já mudaram. Hoje o pai não é tão hierárquico como era. E a mesma coisa acontece com a mãe e os filhos que têm muito mais independência. Isso ocorre por causa da propagação de informação, que se reflete em todos os setores, inclusive na economia. As empresas estão deixando aquela estrutura hierárquica e se organizando em células independentes.

RCE: Como fica essa mudança de cenário para o ensino básico e fundamental?

João Zuffo: Acredito que o ensino vai mudar profundamente nos próximos quinze anos, principalmente no sentido de ser muito mais informatizado. Chamo a atenção para os computadores, pois é possível criar sistemas especializados de computação que tenham o perfil psicológico da criança. Hoje já se usam sistemas especializados desse tipo. Por exemplo, a Amazon ${ }^{4}$, através de um sistema de inteligência artificial, levanta o perfil psicológico dos seus clientes. E a partir dos chats e dos pedidos
3. Algoritmos genéticos são softwares, procedimentos modelados segundo conceitos da genética e da evolução. (N. E.)

4. Disponível em: <http:// www.amazon.com>, site americano de compras on-line. 
on-line do cliente, ela vai mapeando o perfil psicológico, procurando antecipar o pedido freqüentemente. Com certeza $95 \%$ ficam com o produto oferecido. Esse tipo de intervenção estará presente nas escolas em termos de clones educacionais. Serão pequenas máquinas (semelhantes aos joguinhos eletrônicos) com inteligência artificial, adaptadas e programadas conforme a personalidade de cada criança, para direcionar seus estudos. A figura do professor continuaria existindo, porém com função de orientador vocacional, mais ou menos no esquema do orientador de pós-graduação de hoje. Os cursos elementares terão de ser voltados mais para a criatividade e para os aspectos vocacionais da criança. Cada aluno deverá receber a formação a partir de suas aptidões, com atenção especial.

RCE: É por isso que o senhor afirma no seu livro A infoera: o imenso desafio do futuro, que a formação do aluno será mais humanista?

João Zuffo: Sim. A formação tende a ser mais humanista devido a uma série de fatores. Veja bem, a parte técnica tende a perder muito valor por dois motivos: um deles é a enorme automação industrial que vem ocorrendo. Quando existe um software capaz de projetar toda a estrutura de um prédio, e você pode revestir esse prédio com o acabamento que quiser, entrar nele e prever a iluminação, as cores das paredes, saber as condições reais de ventilação e calor, tudo previsto através do computador, podemos dizer que não vamos mais precisar do engenheiro civil. Qualquer pessoa com uma formação básica na área de exatas será capaz de fazer isso. Podemos dimensionar isso para todas as áreas. Nesse aspecto chamo a atenção para a superespecialização que existiu na era pós-industrial e desaparecerá na infoera. As áreas técnicas vão ter menos espaço. Se você comparar a procura pelos cursos de engenharia há quinze, vinte anos, na ordem de 50 candidatos para uma vaga, verá como diminuiu. Hoje não chega a 15. Já na área de humanas, a procura vem crescendo, porque é a que menos sofrerá concorrência das máquinas, dos computadores.

RCE: Como fica esse ensino ainda estanque dividido em áreas específicas?

João Zuffo: Isso tende a se dissolver completamente. Muitas profissões vão se tornar obsoletas. O ensino vai ter de deixar de ser estanque e, mais ainda, precisaremos de um ensino básico muito mais sólido, pois é o único que fica. No resto, haverá um vendaval de mudanças. Não vai adiantar se especializar; o conhecimento ficará obsoleto em um curto espaço de tempo. Será melhor fazer um curso do tipo just in time, quando estamos nos referindo à parte profissional.

5. A Finep é a agência de fomento do Ministério de Ciência e Tecnologia (MCT), responsável pela promoção do desenvolvimento tecnológico e da inovação. (N. E.)
RCE: O senhor tem alguma sugestão para as mudanças que estão ocorrendo no ensino? João Zuffo: Primeiro, teríamos de trabalhar desde agora no desenvolvimento de softwares ligados a nossa própria cultura. O pessoal do exterior já está fazendo isso há tempos, e nós não temos quase nada desenvolvido para o ensino a distância de milhões de pessoas. Poderíamos, dessa forma, resolver o problema do analfabetismo no Brasil de forma muito rápida. Entretanto, não temos nenhuma tecnologia própria. Nós fizemos um pedido para a Finep ${ }^{5}$ de recurso financeiro para desenvolvimento de bases em ensino para milhões, através da 
rede internet, da TV digital e da TV normal e, no entanto, foi negado. Para qualquer país essa tecnologia é fundamental. Não dá para usar as técnicas de ensino convencional. Temos de pensar num ensino voltado para crianças via computadores, utilizando softwares adaptados ao perfil psicológico da criança. Essa máquina tem de ser totalmente interativa. Ela será um companheiro de todas as horas, conversando com a criança, lidando com questões crescentes. A criança terá uma evolução semelhante à que ela obtém na vida normal, sem precisar ir à escola, somente com a convivência. O professor supervisionará um grupo, como se fosse um orientador. Precisamos desenvolver essa tecnologia interativa para que acompanhemos a evolução e depois não precisemos importar. Não podemos demorar. Isso é para logo, já para os próximos dez anos.

RCE: O senhor acha que essa tecnologia para ensino a distância é imprescindível?

João Zuffo: Para fazer inclusão social de todas as pessoas, é imprescindível. É uma forma de aumentar muito a eficiência, inclusive a dos professores que se encontram muito longe dos centros urbanos mais desenvolvidos no Brasil.

RCE: O ensino a distância é eficaz só através do computador ou é preciso alguns momentos presenciais?

João Zuffo: Os momentos presenciais são complementares. Através do ensino a distância o professor será mais eficiente. Ele vai estar ligado a uma rede nacional e terá acesso às melhores tecnologias. Inicialmente é um projeto ${ }^{6}$ de telemedicina ligado à oncologia infantil. Estamos associando seis hospitais - Distrito Federal, Piauí, Rondônia, Santa Catarina, Espírito Santo e Amazonas. O ensino é feito primeiramente em videoconferência, depois os participantes vão analisar protocolos, imagens. Pretendemos fazer isso também na área de ensino de graduação. É um ensino preocupado com a interatividade, que é fundamental para o pessoal fazer perguntas, conversar entre si. É claro que a parte presencial é importante. $\mathrm{O}$ contato seria com um professor local e posteriormente com reuniões anuais presenciais. Na Universidade do Texas, cerca de $60 \%$ dos alunos fazem cursos a distância. A USP aumentaria muito a eficiência do ensino se adotasse maciçamente esse tipo de educação. Poderíamos dobrar ou triplicar o número de vagas sem ter de aumentar o número de professores e onerar a folha de pagamento.

RCE: O Brasil está preparado tecnologicamente para esse tipo de educação?

João Zuffo: Sim, estamos. O que precisamos é desenvolver os nossos próprios softwares. Pegar especialistas da educação, de línguas e integrar num projeto maior, adaptado à nossa cultura, às nossas tradições.

RCE: Como deve ser a formação do professor para lidar com essas mudanças?

João Zuffo: Ele terá de ter uma formação muito sólida. Com as novas tecnologias, ele se adaptará fazendo cursos do tipo just in time. As superespecialidades não vão mais existir, como disse anteriormente. A Poli já começou a fazer mudanças, transformou a engenharia em quatro grandes áreas, extinguiu as especialidades. Podemos dizer que a superespecialização está ficando para trás, pois as ferramentas de softwares vieram para complementar.
6. O Projeto OncoWeb Rede Piloto de Telessaúde em Oncologia Pediátrica, uma parceria entre Unifesp - Universidade Federal de São Paulo, LSI - Laboratório de Sistemas Integrados da USP, Instituto Edumed e Sobope - Sociedade Brasileira de Oncologia Pediátrica, oferece serviços especializados a distância em câncer infantil, no auxílio à prática médica. 
RCE: Quais as profissões que vão ficar obsoletas?

João Zuffo: Digo que a criatividade vai ser fundamental. Tudo indica que as profissões puramente técnicas irão desaparecer. As atividades voltadas para o bem-estar pessoal terão grande desenvolvimento. Haverá, também, um crescimento enorme da saúde em casa. Devido à facilidade da comunicação, será possível monitorar o paciente inserindo um chip nele, controlando fluxo sangüíneo, pressão, temperatura, tudo a distância. As profissões voltadas às questões teóricas, como Física, Matemática, Informática, vão exigir muitas pessoas e muito trabalho. As áreas voltadas à geração de conteúdo e à criação tendem a crescer.

RCE: Com essas mudanças, a tendência é acabar as áreas de exatas para predominar a de humanas?

João Zuffo: Elas vão interagir. Não é que vão acabar, elas mudarão. Assim como mudou a engenharia de cinqüenta anos atrás, em que se usava régua de cálculo. Vai diminuir inclusive a necessidade de engenheiros, porque um engenheiro trabalhando à frente de uma workstation faz a produção de dez ou cem engenheiros. A automação vai ser muito mais intensa na área de serviços do que na área industrial. Hoje você tem mais desemprego na área bancária do que na área industrial. As secretárias estão sendo substituídas pelo viva-voz da IBM. E isso as pessoas normalmente não prevêem. Elas acham que as coisas permanecem como estão, enquanto as mudanças ocorrem de uma maneira muito rápida. Haverá cada vez mais desemprego e o governo precisa fazer mudanças muito mais profundas do que as que estão ocorrendo. A reforma da previdência é imprescindível. Se tivermos uma concentração de renda como há atualmente, vamos entrar num ciclo recessivo em muito pouco tempo. Veja o caso do Japão e dos Estados Unidos, que estão vivendo num ciclo recessivo por esse motivo. Alguns analistas de mercado acham que daqui a uns quinze, vinte anos o dinheiro não circulará mais entre as pessoas pobres. Serão distribuídos gratuitamente alimentos e coisas mais baratas. $\mathrm{O}$ custo das coisas massificadas está tendendo a zero. Quando eu era criança, para comprar uma chave de fenda levava semanas para juntar o dinheiro. Hoje, compro uma dúzia de chaves de fenda por um ou dois reais. Essa proliferação de lojas de um ou dois reais é prova da tendência de que o custo das coisas está tendendo a zero. Tudo o que for industrializado, terá o preço tendendo a zero; e tudo o que tiver uma característica humana, artesanal, vai ser valorizado. As relações sociais irão mudar drasticamente, como mudou quando saímos da era agropastoril para a industrial. O trabalho sistemático foi muito criticado. O emprego vitalício da era industrial está desaparecendo. O mercado exigirá trabalho criativo, que tende a ser em casa e mais individual.

RCE: Quais são suas propostas de mudança?

João Zuffo: Minhas propostas de mudança são as de que as fontes para a previdência sejam outras que não essas de agora. Impostos indiretos, tipo ICMS e IPI, tinham de desaparecer e deveria aumentar-se o imposto sobre circulação de riquezas. Exatamente para você poder fazer frente às mudanças sociais que estão ocorrendo. O pessoal critica muito o IPVA, no entanto, acho que os impos- 
tos cobrados deveriam seguir mais esse sentido do que o de impostos indiretos, para evitar a recessão, e nós estamos a caminho de uma deflação. A infoera é deflacionária intrinsecamente. O preço de todas as coisas está tendendo a zero. Ela não precisa ser obrigatoriamente recessiva, e para isso é preciso manter ou substituir a massa salarial que está sendo diminuída de uma forma muito drástica, devido ao desmantelamento do emprego vitalício. Será preciso subsidiar as pessoas de maneira que elas possam consumir. Quando estive no Japão em 1999, o governo japonês estava distribuindo cupons de compras para a população mais pobre para poder dinamizar a economia. Provavelmente o futuro vai ser assim. As comidas e os bens de menor custo vão ser distribuídos de graça.

RCE: Como fica essa questão da exclusão digital?

João Zuffo: Isso envolve um perigo muito grande. A exclusão social e a exclusão digital estão intrinsecamente ligadas. Se houver uma exclusão social muito mais drástica, pode ser que a sociedade viva em castas, como acontecia na antiga Índia. E isso seria gerado pela exclusão digital. As pessoas com acesso às tecnologias digitais terão mais facilidade de ascender socialmente do que as que não têm.

RCE: É do conhecimento que o Fust - Fundo de Universalização dos Serviços de Telecomunicações vai disponibilizar 100 milhões para serem usados em projetos de inclusão digital. Também foram criados os infocentros, telecentros. O senhor acha essas medidas importantes para diminuir o problema da exclusão digital?

João Zuffo: Acho isso fundamental. A própria TV digital é importante para isso. Por exemplo, estamos desenvolvendo na Poli um sistema de transcodificação da TV analógica para a TV digital, que estamos chamando de Top Box ${ }^{7}$, o qual inclui acesso à internet e interatividade. Com esse equipamento qualquer um poderá interagir com a internet através do seu televisor comum. A TV digital será implantada nos próximos vinte anos e vai ser um fator-chave para a inclusão social. Hoje você tem praticamente $70 \%$ a $80 \%$ dos lares brasileiros com televisão. Se a TV for interativa, estaremos incluindo automaticamente um percentual muito grande de pessoas dentro do sistema.

RCE: Como será TV Digital?

João Zuffo: A TV analógica, que é a que temos hoje em nossas casas, não permite uma série de coisas. Já a TV digital possibilita interagir com a estação emissora e ainda enviar sinais nos dois sentidos. A rigor, existem vários tipos de TV digital. Por exemplo, o tipo $\mathrm{HDTV}^{8}$ é muito caro para nós brasileiros. O problema é que temos tendência de adotar o sistema de TV mais ligado à necessidade dos países desenvolvidos, que vai mais no sentido de HDTV, aumentar a definição da TV, corrigir uma série de facilidades do computador dentro da TV. Outra forma, que considero mais propícia para nossa realidade, é ter um sistema em camadas, no qual pode existir tanto um sistema mais simples como um mais complexo. A vantagem do sistema em camadas é que numa fase de transição, como a que deveremos passar nos próximos anos, você pode receber sinais do Top Box, da TV Digital e da TV analógica; assim não fica restrito a apenas um sistema.
7. Set Top Box: equipamento eletrônico utilizado em aparelhos de televisão que permite a recepção e decodificação de sinais digitais de áudio e vídeo e também serviços interativos como videoconferência, educação a distância etc. (N. E.)

8. HDTV - High-Definition Television é uma TV digital de alta definição, que gera imagens muito mais nítidas e definidas. (N. E.) 
RCE: Como se dá essa interação na TV digital?

João Zuffo: Essa interação pode se dar ou através de um teclado simples, ou pela voz. Por enquanto seria por meio do teclado simples. Estamos desenvolvendo um tipo de Top Box que terá um custo em torno de 40 dólares, enquanto o Top Box convencional sairá em torno de mil dólares. A internet tende a ser um meio de comunicação cada vez mais importante. As pessoas que não têm acesso à internet sofrem não só exclusão digital, mas também social. Hoje, no governo, a maior parte das coisas vem pela internet. As pessoas que não têm acesso a essa tecnologia estão cortadas do esquema. Precisaria baratear o custo dos computadores. É possível fazer um computador hoje por 200 dólares, usando sistema operacional Linux, softwares livres.

RCE: Mas e as placas, os componentes que são todos importados?

João Zuffo: Você simplifica todos esses componentes. Dá para fazer componentes de cápsulas. Para o acesso à internet você não precisa de um computador de primeira linha, mas necessita de uma linha telefônica impreterivelmente. Se não me engano, o acesso à internet no Brasil está em torno de 12 milhões de pessoas. Esse número é bem superior ao da TV a cabo.

RCE: Quais as propostas que o senhor tem para ampliação do uso das novas tecnologias? João Zuffo: Tornar o computador mais amigável. Acho que a comunicação pela voz é fundamental; a Intel está entrando nisso. A próxima geração de computadores que ela lançará já vai ter a comunicação pela voz, que estará intrínseca à placa mãe. Você poderá dar comando falado e o computador irá entender. A segunda fase seria o computador conseguir interpretar seus gestos. A partir da câmera que fica em cima do computador, você piscará e o computador entenderá sua piscada, ou seja, ele vai operar de acordo com seus gestos.

RCE: Com o advento das novas tecnologias, os meios de comunicação tradicionais como o rádio, a TV, o jornal tendem a desaparecer?

João Zuffo: Vão mudar profundamente. Muitos autores dizem que a TV broadcasting, a tradicional, tende a desaparecer em questão de poucos anos. Está acontecendo uma série de fenômenos e as pessoas terão consciência de que o tempo está passando muito depressa. Então elas serão cada vez mais exigentes com relação ao tipo de notícia que querem receber. As notícias do futuro tendem a ser personalizadas. Por exemplo, o jornal $O$ Estado de $S$. Paulo já tem esse esquema e a tendência é só crescer. As notícias vão surgir de acordo com o interesse psicológico. Isso afeta tudo, as vendas, a propaganda. Estamos entrando numa era em que não existirá mais a produção em massa como foi na época do Henry Ford, em 1918. O fordismo afetou inclusive a forma de se fazer propaganda, a radiodifusão, a TV broadcasting. Agora a tendência é a personalização das coisas. Alguns acham que o mundo de amanhã vai ser o mundo do artesão, do artesanato distribuído. As empresas terão grandes sistemas de computação interagindo com o cliente, por exemplo, o cliente é quem vai especificar como será o seu carro, como ele quer o pára-choque, o pára-lama etc. Depois de uma semana, a empresa entrega o carro do jeito que ele especificou. $\mathrm{O}$ cliente participará da personalização dos produtos industriais. 
RCE: A produção em massa vai continuar existindo?

João Zuffo: Cada vez menos. Diminuíram os valores das coisas produzidas maciçamente. As pessoas tentarão se distinguir das outras através da personalização dos seus produtos. Imagine um mundo em que você tenha uma supercapacidade de comunicação, em que se consiga interagir com o fornecedor final. Isso vai gerar uma série de outros fenômenos. A intermediação convencional desaparecerá e você vai poder entrar em contato com seu produtor inicial, sem intermediários. Falar que o setor terciário da economia irá absorver a mão-de-obra é falso. Vão desaparecer também os empregos do setor terciário, da área de serviços. Sobreviverá quem oferecer um diferencial que agregue valor ao trabalho.

RCE: Quais as áreas que estão em expansão e o que muda com isso?

João Zuffo: É fato que a microeletrônica está aumentando cada vez mais e tem dobrado o número de componentes a cada dois anos, gerando um crescimento na faixa de $50 \%$ ao ano. Outra área em grande expansão é a das telecomunicações, que cresce em nível mundial em média $78 \%$ ao ano. Acredita-se que por volta de 2005, 2006, tudo estará ligado a todos via internet. Isso significa que serão milhões de computadores ligados em rede, bilhões de seres humanos e bilhões de chips. Os chips vão estar em qualquer lugar possível de se imaginar. Estarão nas paredes, monitorando a composição do solo, monitorando a saúde dos animais etc. Será uma gigantesca rede mundial em que as comunicações terão uma capacidade de memória incrível. Para se ter uma idéia, é só contar quantos telefones celulares tínhamos há cinco anos e quantos temos hoje. $\mathrm{O}$ número de celulares está quase ultrapassando o de telefones fixos, porque o celular é algo pessoal e às vezes as pessoas têm dois, três telefones celulares para atender certas pessoas com maior prioridade que outras.

RCE: Isso gera um certo medo. Quem terá o poder de controlar essa rede?

João Zuffo: Existirão grandes perigos, não só no sentido de quem irá deter o poder dessa rede gigantesca. Também precisamos nos preocupar com o seguinte: onde há memória e comunicação, há inteligência. Há cerca de 700 milhões de anos, quando começou a vida na Terra, os animais eram simples e não tinham um sistema de DNA. Levou aproximadamente 400 milhões de anos para as células comporem o DNA. Quando esse processo ocorreu, as células inventaram um sistema eficiente de memória para passar às outras gerações. Mesmo quando esses seres unicelulares foram se associando e formando os corais, ainda não existia a comunicação. Quando houve a comunicação, começaram a se formar os seres mais complexos. E essa complexidade foi se ampliando, baseada no sentido da comunicação e da memória. E é por isso que se diz que a rede mundial pode acabar criando uma inteligência própria, por ter como componente básico a memória e a comunicação, e formando quase uma consciência mundial.

RCE: Podemos dizer que existe um grupo de pessoas controlando isso?

João Zuffo: Sim. Tanto podem ser algumas pessoas como até alguns países. Os americanos monitoram praticamente todos os telefonemas em nível mundial. Eles têm supercomputadores que detectam palavras-chave. Se você fala 
BinLaden, eles vão captar seu telefonema, escutar e gravar inteiramente. Esse monitoramento mundial já existe.

RCE: Mas há alguma saída para os países em desenvolvimento que não têm capacidade de desenvolver toda essa tecnologia?

João Zuffo: Há algumas oportunidades, mas a situação é complicada. Pode ser que tenha, eu não diria uma tendência de modo único, mas uma infinidade de grandes irmãos controlando uma sociedade. Grandes empresas, por exemplo, como é caso da Amazon. A privacidade está ameaçada, assim como a segurança do ser humano de modo geral.

RCE: $O$ que seria isso?

João Zuffo: Em 1946 foi tornado público o ENIAC, o computador desenvolvido durante a guerra. Trinta anos depois, em 1976, surgiu o Apple. A fase dos supercomputadores desapareceu e está começando a fase dos microprocessadores. Daqui a vinte anos a informática vai estar "pervasiva”, ou seja, estará penetrando em todas as coisas, em todos os materiais. Poderei pedir em voz alta qualquer coisa para ser feito que o computador providenciará. São as chamadas casas inteligentes. É isso que é pervasivo. Esse é o mundo que nos espera para os próximos trinta anos. Vai haver um grande distanciamento da realidade: não distinguiremos mais o que é real do que não é, por causa da realidade virtual e devido à síntese em tempo real de avatares ${ }^{9}$, de imagens humanas semelhantes a humanos. É o caso dos desenhos animados que estão cada vez mais parecidos com os seres humanos. Em dez anos será possível gerar isso em tempo real. Tal recurso vai tornar as pessoas menos sensíveis para as dores dos outros. Poderá haver avatares seus que respondam perguntas simples, de acordo com seu perfil psicológico, agindo como você agiria. Irá mudar todo o relacionamento humano.

9. Avatar: palavra indiana que significa descendência. A princípio, os Avatares eram deuses que passeavam na terra com forma humana. (N. E.)
Resumo: Em entrevista a Comunicação \& Educação, o professor livre-docente, João Antonio Zuffo, da Escola Politécnica da USP, fala de seus estudos e expectativas sobre o advento das novas tecnologias. Zuffo mostra a revolução que a Internet vem provocando ao conectar o mundo em uma grande e única rede mundial capaz de controlar todas as informações; e quanto a informática tem revolucionado as atividades profissionais e as relações humanas, como também a educação em todas as suas instâncias. Ressalta a importância do ensino a distância desenvolvido com tecnologia propriamente brasileira, e como a chegada da TV Digital irá contribuir para diminuir a exclusão digital.

Palavras-chave: novas tecnologias, infoera, rede mundial, TV Digital, educação a distância.
Abstract: Interviewed by the Communication \& Education journal, João Antonio Zuffo, associate professor of Escola Politécnica of USP, talks about his research and expectations on the advent of new technologies. Zuffo shows the revolution that Internet is provoking by connecting the world in a huge and unique net able to control all information and how information technology has revolutionized professional activities and human relations, as well as education in all instances. He points out the importance of the long distance education programs developed with Brazilian-created technology and also how the arrival of digital television will contribute to diminish digital exclusion.

Keywords: new technologies, Information Era, world net, digital television, long distance education. 